OPEN ACCESS

Edited by:

Tom Defoirdt,

Ghent University, Belgium

Reviewed by:

Raphaël Lami,

Sorbonne Université, France

Vipin Chandra Kalia,

Konkuk University, South Korea

*Correspondence:

Jianrong $L$

lijianrong@bhu.edu.cn

Specialty section:

This article was submitted to

Infectious Diseases,

a section of the journal

Frontiers in Microbiology

Received: 07 October 2018 Accepted: 21 December 2018

Published: 09 January 2019

Citation:

Li T, Mei Y, He B, Sun X and Li J (2019) Reducing Quorum

Sensing-Mediated Virulence Factor

Expression and Biofilm Formation in Hafnia alvei by Using the Potential

Quorum Sensing Inhibitor L-Carvone.

Front. Microbiol. 9:3324.

doi: 10.3389/fmicb.2018.03324

\section{Reducing Quorum Sensing-Mediated Virulence Factor Expression and Biofilm Formation in Hafnia alvei by Using the Potential Quorum Sensing Inhibitor L-Carvone}

\author{
Tingting $\mathrm{Li}^{1}$, Yongchao $\mathrm{Me}^{2,3}$, Binbin $\mathrm{He}^{2,3}$, Xiaojia Sun ${ }^{2,3}$ and Jianrong $\mathrm{Li}^{2,3 *}$ \\ ${ }^{1}$ Key Laboratory of Biotechnology and Bioresources Utilization (Dalian Minzu University), Ministry of Education, Dalian, China, \\ ${ }^{2}$ College of Food Science and Technology, Bohai University, Jinzhou, China, ${ }^{3}$ National \& Local Joint Engineering Research \\ Center of Storage, Processing and Safety Control Technology for Fresh Agricultural and Aquatic Products, Jinzhou, China
}

Quorum sensing (QS), one of the most remarkable microbiological discoveries, is considered a global gene regulatory mechanism for various traits in bacteria, including virulence and spoilage. Hafnia alvei, an opportunistic pathogen and a dominant psychrophile, uses the lux-type QS system to regulate the production of virulence factors and biofilms, which are harmful to the food industry. Based on the QS interference approach, this study aimed to reveal the efficacy of L-carvone at sublethal concentrations on QS-regulated virulence factors and biofilm formation in H. alvei. QS inhibitory activity was demonstrated by the reduction in swinging motility (61.49\%), swarming motility (74.94\%), biofilm formation (52.41\%) and acyl-homoserine lactone (AHL) production $(0.5 \mu \mathrm{L} / \mathrm{mL})$. Additionally, in silico analysis and RT-qPCR studies for AHL synthase Hall and QS transcriptional regulator HalR revealed a plausible molecular mechanism for QS inhibition by L-carvone. These findings suggest that L-carvone (a main component of spearmint essential oils) could be used as a novel quorum sensing inhibitor to control $H$. alvei in the food industry.

Keywords: Hafnia alvei, L-carvone, quorum sensing inhibitor, in silico analysis, RT-qPCR

\section{INTRODUCTION}

Hafnia alvei is a Gram-negative, facultatively anaerobic, rod-shaped, motile bacterium of the family Enterobacteriaceae; it is an opportunistic pathogen and a dominant psychrophile found in putrid food (Vivas et al., 2008). It has been widely isolated from different food products, such as raw meat, dairy and aquatic products, and specially from various packed food products stored at low temperatures (Kennedy et al., 2010; Chen et al., 2011; Tan et al., 2014). Based on these characteristics, $H$. alvei is often considered a specific spoilage organism (SSO) that causes severe nutrition and safety problems in these food matrices by producing extracellular enzymes and siderophores, and forming biofilms. Recent studies have described the key roles of virulence factors 
and biofilm production in $H$. alvei, which is regulated by quorum sensing (QS) systems (Viana et al., 2009; Hou et al., 2017b).

Quorum sensing is a process that allows single-cell organisms (like bacteria) cooperate, communicate, and act collectively. By this process, they can produce, release, detect, and establish connections with small chemical molecules called autoinducers, which in Gram-negative bacteria are acyl-homoserine lactones (AHLs). Thus, AHL-mediated QS systems are usually composed of the LuxI-type autoinducer synthetase, and cytoplasmic LuxR-type proteins, which are receptors activated by AHLs (Ng and Bassler, 2009). Among these two proteins, LuxR-type proteins have more complex functions. With the increase of bacterial density (achieving a certain threshold), the ligand-binding domain of the LuxR-type proteins will bind with AHLs, which will cause changes in the protein conformation and stimulate the formation of AI-LuxR compound proteins, and lead to the binding of the DNA-binding domain of these compound proteins to target genes, thereby regulating the expression of bacterial multiplex phenotypic features such as virulence factors and biofilms (Almeida et al., 2016). Therefore, interfering with AHL-mediated QS systems by using certain compounds, generally called QS inhibitors (QSIs), may be a better strategy to prevent bacterial food spoilage. Compared to antibiotics and antiseptics, QSIs aim to make the bacteria 'surrender' instead of killing them, which would weaken them from having resistance (Defoirdt, 2017).

Nowadays, many synthetic and natural products have been called QSIs; however, only a few of them have a therapeutic value, due to the instability or high toxicity of most other compounds (Defoirdt et al., 2013). Due to the property of low toxicity, some natural compounds from spice plants have been widely used as antimicrobial agents in the food industry, such as curcumin, vanillin, menthol, and cinnamaldehyde (Fitzgerald et al., 2003; Husain et al., 2015; Ding et al., 2017). Therefore, extracting natural compounds from spice plants to obtain effective QSIs has become a promising research hotspot. $\mathrm{L}$-Carvone (or (R4)-(-)-carvone), a monoterpene, is the main component of spearmint essential oils from traditional spice plants and medical herbs. It is widely applied in the food field; it is used to enhance the fragrance and flavor in cooking, and in the beverage and the chewing gum industries (de Carvalho and da Fonseca, 2006). In many studies, L-carvone has been reported as an antimicrobial agent for foodborne pathogenic microorganisms (Friedman et al., 2002; Porfírio et al., 2017); however, there is still limited information about the relationship between spoilage bacteria and QSIs. Therefore, our study involves the characterization of the L-carvone-mediated inhibition of the QS activity of the biosensor strain Chromobacterium violaceum CV026, and subsequently, the determination of the effect of L-carvone on virulence factor and biofilm production in the spoilage bacterium $H$. alvei. Additionally, we further investigated the underlying mechanism of L-carvone as a potential QSI in $H$. alvei, by using the in silico analysis and RT-qPCR techniques. In this regard, the study has provided new information about the application of L-carvone as potential QSI and reference values for the effective control of spoilage bacteria.

\section{MATERIALS AND METHODS}

\section{Reagents, Bacterial Strains, and Growth Conditions}

L-Carvone ( $\geq 99 \%$ purity) and AHL standards including $\mathrm{C}_{4}$-HSL, $\mathrm{C}_{6}$-HSL, $\mathrm{C}_{8}$-HSL, $\mathrm{C}_{10}-\mathrm{HSL}, \mathrm{C}_{12}-\mathrm{HSL}$, and $\mathrm{C}_{14}$-HSL were obtained from Sigma-Aldrich (United States). The molecular biology reagents were purchased from Thermo Fisher Scientific (Shanghai, China). Other chemical reagents used in this study were of analytical grade, except for methanol (Chromatographic grade). The bacterial strains used in this study were $C$. violaceum CV026 and H. alvei Ha-01, as an AHL-reporter organism and a test strain, respectively. C. violaceum CV026 was provided by Dr. Yang (Xinjiang Shihezi University, Xinjiang, China) and $H$. alvei (ATCC 13337) Ha-01 was originally isolated and identified from putrid turbot by our group. C. violaceum CV026 was a mini-Tn5 mutant derived from C. violaceum ATCC 31532; it was kanamycin-resistant. It could respond only when exogenous AHLs were present, after which it produced the characteristic violet pigment, violacein. Both the strains were overnight cultured in Luria-Bertani (LB) broth (Qingdao Hopebio Co., Ltd., China), at $28^{\circ} \mathrm{C}$ and $160 \mathrm{rpm}$; however, the LB broth culture medium for CV026 required $20 \mu \mathrm{g} / \mathrm{mL}$ kanamycin.

\section{Antibacterial Assay Determination of the Minimum Inhibitory Concentration (MIC) of L-Carvone}

The MIC of L-carvone against the selected bacteria was determined using the Oxford cup assay method, as described by Diao et al. (2014). Overnight-cultured $\left(\mathrm{OD}_{600}=0.5,250 \mu \mathrm{L}\right)$ C. violaceum CV026 or H. alvei was inoculated in LB nutrient agar $(25 \mathrm{~mL})$ and poured into a plate that accommodated two autoclaved Oxford cups, which were removed when the agar solidified. Two hundred microliters of L-carvone (diluted to 2.0, $1.0,0.5,0.25,0.125$, and $0.0625 \mu \mathrm{L} / \mathrm{mL}$ using sterile water) were added to the wells, while sterile water served as the control. The plates were incubated at $28^{\circ} \mathrm{C}$ for $36 \mathrm{~h}$ and the bacterial growth states were observed. The minimum concentration at which there was no visible growth was defined as the MIC. Then, sub-MICs were selected for the further experiments using the above strains.

\section{Determination of QSI Activity Violacein Inhibitory Activity}

The violacein inhibitory activity was determined by adopting the method described by Ia et al. (2012), with slight modifications. Overnight-cultured C. violaceum CV026 $(250 \mu \mathrm{L})$ was inoculated in LB nutrient agar $(25 \mathrm{~mL})$ containing $10 \mu \mathrm{L}$ of exogenous AHLs $\left(\mathrm{C}_{6}\right.$-HSL, $\left.2 \mathrm{mg} / \mathrm{mL}\right)$. Afterwards, $200 \mu \mathrm{L}$ of L-carvone at the sub-MICs was added to each well (diameter, $6 \mathrm{~mm}$ ) on the plates, while $200 \mu \mathrm{L}$ of sterilized water was used as the negative control. The plates were incubated at $28^{\circ} \mathrm{C}$ for $24 \mathrm{~h}$, and the bacterial growth status was observed. Once no violet pigment was produced around the well, the violacein inhibitory activity was determined. 


\section{Quantitative Analysis of Violacein Production}

Violacein produced by C. violaceum CV026 exposed to different concentrations $(0.5,0.25,0.125$, and $0.0625 \mu \mathrm{L} / \mathrm{mL})$ of L-carvone was quantified as previously described by Choo et al. (2006). Different concentrations of L-carvone (described above) were mixed in $10 \mathrm{~mL}$ of $\mathrm{LB}$ broth containing $20 \mu \mathrm{g} / \mathrm{mL} \mathrm{C}_{6}$-HSL, along with C. violaceum CV026 overnight cultures, and incubated at $28^{\circ} \mathrm{C}$ for $48 \mathrm{~h}$ with shaking $(160 \mathrm{rpm})$. At the same time, a similar experiment without $\mathrm{C}_{6}$-HSL was performed, and the $\mathrm{OD}_{595}$ was measured to determine the effect of the above concentrations of L-carvone on the growth of the CV026.

The violacein pigment was extracted according to the method described by Kumar et al. (2015) with modifications. The cultures in each treatment group were vortexed, and $300 \mu \mathrm{L}$ of these mixed cultures were taken in 1.5-mL tubes (Eppendorf). They were lysed (for $15 \mathrm{~s}$ ) using 10\% sodium dodecyl sulfate (SDS, $150 \mu \mathrm{L}$ ) at room temperature, and then, extracted (for $5 \mathrm{~s}$ ) using butyl alcohol $(600 \mu \mathrm{L})$. Finally, this solution was centrifuged $(9,000 \mathrm{~g}$ for $5 \mathrm{~min})$; violacein was contained in the organic layer. Then, the $\mathrm{OD}_{595}$ of each supernatant was measured in a 96-well microtiter plate.

\section{Assay for Biofilm Formation}

The 1.5-mL Eppendorf tubes (polypropylene material) were autoclaved, and the $H$. alvei overnight cultures $(100 \mu \mathrm{L})$ were inoculated in $1 \mathrm{~mL}$ of $\mathrm{LB}$ broth containing various concentrations $(0.5,0.25,0.125$, and $0.0625 \mu \mathrm{L} / \mathrm{mL})$ of L-carvone. Sterile water or $20 \mu \mathrm{g} / \mathrm{mL} \mathrm{C}_{6}$-HSL was used as the negative control or positive control (absence of L-carvone), respectively. The tubes were statically incubated at $28^{\circ} \mathrm{C}$ for $48 \mathrm{~h}$. Then, the determination of biofilm was performed as described previously (Rode et al., 2007), with minor modifications. The cultures were discarded, and each tube was rinsed thrice with sterile water. The tubes were then naturally dried for $40 \mathrm{~min}$ and stained with $1 \mathrm{~mL}$ of $0.1 \%$ crystal violet (w/v) for $15 \mathrm{~min}$ at room temperature. After washing with sterile water, the biofilms were extracted using 33\% acetic acid. The biofilm solutions were then transferred to a clean 96-well plate, and the $\mathrm{OD}_{595}$ values were measured using microplate photometers (Bio-Rad, United States).

\section{Visualization of Biofilms by CLSM and SEM}

To pre-form the biofilms, pieces of zinc $(6 \mathrm{~mm} \times 6 \mathrm{~mm} \times 0.2 \mathrm{~mm})$ were polished and immersed in LB broth containing sub-MICs of L-carvone or $20 \mu \mathrm{g} / \mathrm{mL}$ of $\mathrm{C}_{6}$-HSL in $90-\mathrm{mm}$ sterile plates (Thermo, United States). Overnight cultures of $H$. alvei $\left(\mathrm{OD}_{600}=0.5,100 \mu \mathrm{L}\right)$ were inoculated in these plates and then statically incubated. After cultivation (at $28^{\circ} \mathrm{C}$ for $48 \mathrm{~h}$ ), a piece of zinc (with an adhered biofilm) was transferred to a clean sterile plate and washed thrice with sterile phosphate buffer saline (PBS, $\mathrm{pH}$ 7.4) to remove the planktonic cells. For visualization by confocal laser scanning microscopy (CLSM), this zinc piece was stained with $0.01 \%(\mathrm{w} / \mathrm{v})$ acridine orange (AO, dissolved in PBS) for $15 \mathrm{~min}$ in the dark. Then, the excessive
AO was removed by washing with PBS, followed by fixing with antifade mounting medium Fluoromount-G ${ }^{\mathrm{TM}}$ (Yeasen, China) for $15 \mathrm{~min}$ under the same conditions. Finally, the samples were observed by CLSM (Leica SP5, German) (emission: $525 \mathrm{~nm}$, excitation: $488 \mathrm{~nm}$ ). For visualization analysis by scanning electron microscopy (SEM), the zinc piece was soaked in $2.5 \%$ glutaraldehyde $(\mathrm{v} / \mathrm{v})$ at $4^{\circ} \mathrm{C}$ for $5 \mathrm{~h}$, dehydrated in graded ethanol (15 min for each grade). Subsequently, the SEM sample was obtained after drying with sterile air.

\section{Swimming and Swarming Motility Assay}

Motility experiments were performed on swimming $(1 \%[\mathrm{w} / \mathrm{v}]$ tryptone, $0.5 \%[\mathrm{w} / \mathrm{v}] \mathrm{NaCl}$, and $0.3 \%[\mathrm{w} / \mathrm{v}]$ agar) or swarming $(1 \%[\mathrm{w} / \mathrm{v}]$ peptone, $0.5 \%[\mathrm{w} / \mathrm{v}] \mathrm{NaCl}, 0.5 \%[\mathrm{w} / \mathrm{v}] \mathrm{D}$-fructose, and $0.6 \%[\mathrm{w} / \mathrm{v}]$ agar) agar plates, as previously described (de la Fuente-Núñez et al., 2012), but with some modifications. These agar plates were supplemented with different concentrations $(0.5,0.25,0.125$, and $0.0625 \mu \mathrm{L} / \mathrm{mL})$ of the L-carvone, before the agar solidified. Then, $5 \mu \mathrm{L}$ of $H$. alvei overnight cultures $\left(\mathrm{OD}_{600}=0.5\right)$ was inoculated at the center of the solidified plates, and the plate was incubated statically at $28^{\circ} \mathrm{C}$ for $48 \mathrm{~h}$. The motility of $H$. alvei was evaluated by measuring the diameter of the swimming and swarming colonies. Plates supplemented with sterile water or $20 \mu \mathrm{g} / \mathrm{mL} \mathrm{C}_{6}$-HSL were used as a negative or positive control, respectively. At least three independent experiments for motility assays were performed.

\section{AHL Analysis by GC-MS AHLs Extraction}

Dilutions (1/100) of $H$. alvei overnight cultures were incubated in LB broth $(200 \mathrm{~mL})$ in the presence of L-carvone $(0.5,0.25$, 0.125 , and $0.0625 \mu \mathrm{L} / \mathrm{mL}$ ) for $24 \mathrm{~h}$ at $28^{\circ} \mathrm{C}$ in an Erlenmeyer flask. Bacterial cells were removed by centrifugation $(9,000 \mathrm{~g}$ for $15 \mathrm{~min})$. The supernatants were extracted using ethyl acetate supplemented with $0.1 \%$ acetic acid thrice, and then, the organic phases were evaporated using a rotary evaporator. The residues were re-dissolved in methanol $(1 \mathrm{~mL})$ and filtered through a $0.22-\mu \mathrm{m}$ membrane (FilterBio, China) for GCMS detection. For comparison, LB broth in the absence of L-carvone was used. $\mathrm{C}_{14}-\mathrm{HSL}$, as an internal standard, was added to each of the AHL samples at a concentration of $5 \mu \mathrm{g} / \mathrm{mL}$.

\section{GC-MS Detection}

The AHL samples of $H$. alvei were further analyzed by GCMS (7890N/5975, Agilent, United States), according to the method described by Zhu et al. (2016). A HP-5 MS capillary column $(30 \mathrm{~m}$ length $\times 0.25 \mathrm{~mm}$ internal diameter $\times 0.25 \mu \mathrm{m}$ film thickness) was used for the chromatographic separation of the AHLs. The injection volume was $1 \mu \mathrm{L}$, using a slit ratio of 50:1. The injector temperature was maintained at $200^{\circ} \mathrm{C}$ and the oven temperature was automated from 150 to $220^{\circ} \mathrm{C}$ at a rate of $10^{\circ} \mathrm{C} / \mathrm{min}$, followed by a $5^{\circ} \mathrm{C} / \mathrm{min}$ increase to $250^{\circ} \mathrm{C}$, and from 250 to $252.5^{\circ} \mathrm{C}$ at $0.5^{\circ} \mathrm{C} / \mathrm{min}$, with helium as the carrier gas, at a flow rate of $1 \mathrm{~mL} / \mathrm{min}$. The mass spectrometry conditions were as follows: the electron 
ionization source was set to $70 \mathrm{eV}$, the MS Quad temperature was $150^{\circ} \mathrm{C}$, the emission current was $500 \mu \mathrm{A}$, the MS Source temperature was $230^{\circ} \mathrm{C}$. Data were acquired using the full-scan mode $(\mathrm{m} / \mathrm{z} 35-800)$ and selected ion monitoring (SIM) mode $(\mathrm{m} / \mathrm{z} 143)$.

\section{RT-qPCR Analysis}

Hafnia alvei was cultured in LB broth with sub-MICs of L-carvone at $28^{\circ} \mathrm{C}$ for growth until the logarithmic phase. $H$. alvei cultured without L-carvone was used as a negative control, while $H$. alvei cultured with $\mathrm{C}_{6}$-HSL was used as a positive control. Total RNA was isolated from $H$. alvei using TRIzol Reagent (Thermo Scientific, United States), according to the manufacturer's guidelines. The quality of the isolated RNA was checked using standard agarose gel electrophoresis. The single-stranded cDNA was prepared in accordance with the protocol of RevertAid First Strand cDNA Synthesis Kit \& DNase I (Thermo Scientific, United States), as stated by the manufacturer. The RT-qPCR experiment was performed by using BIO-RAD CFX Connect ${ }^{\mathrm{TM}}$ Real-Time PCR test system (BIO-RAD, United States) and Power SYBR ${ }^{\circledR}$ Green PCR Master Mix (Applied Biosystems, United States). The sequences of primers are listed in Table 1. The housekeeping gene $16 \mathrm{~S}$ rRNA was used as an internal reference. The conditions for RT-qPCR were as follows: initial denaturation at $95^{\circ} \mathrm{C}$ for $3 \mathrm{~min}$, and $95^{\circ} \mathrm{C}$ for $10 \mathrm{~s}, 55^{\circ} \mathrm{C}$ for $20 \mathrm{~s}$ for annealing, $72^{\circ} \mathrm{C}$ for $20 \mathrm{~s}$ for extension, and $75^{\circ} \mathrm{C}$ for $5 \mathrm{~s}$ for collecting the fluorescence signal; 40 cycles were run. The melt curve was established in the range of $65-95^{\circ} \mathrm{C}$. The relative expression of the objective genes was calculated by using the $2^{-\Delta \Delta C T}$ method, as previously described by Livak and Schmittgen (2001).

\section{In silico Analysis}

The lux-type protein sequences of $H$. alvei were HalI (acyl-homoserine-lactone synthase, AAP30849.1) and HalR (transcriptional regulators, AAP30848.1) and downloaded from the $\mathrm{NCBI}^{1}$. The models of these proteins were built and assessed the online tools SWISS-MODEL ${ }^{2}$ (Bertoni et al., 2017; Bienert et al., 2017; Waterhouse et al., 2018) for docking studies.

${ }^{1}$ https://www.ncbi.nlm.nih.gov/

${ }^{2}$ https://www.swissmodel.expasy.org/

TABLE 1 | List of target genes and their respective primers used for RT-qPCR analysis.

\begin{tabular}{|c|c|c|c|}
\hline Target gene & Primer type & Sequence $\left(5^{\prime} \rightarrow 3^{\prime}\right)$ & $\begin{array}{c}\text { Amplicon } \\
\text { size (bp) }\end{array}$ \\
\hline \multirow[t]{2}{*}{$16 S$ rRNA } & Forward & GTCTGCAACTCGACTCCATGA & 121 \\
\hline & Reverse & CTITGCAACCCACTCCCATG & \\
\hline \multirow[t]{2}{*}{ hall } & Forward & CGGCTTGATTCCACTTCACC & 132 \\
\hline & Reverse & GGGTCTGTATGAAGGGCAGT & \\
\hline \multirow[t]{2}{*}{ halR } & Forward & CGGCTATACTITCGTCCTGC & 179 \\
\hline & Reverse & CTTCCGAAACTGACTGCACG & \\
\hline
\end{tabular}

The lux-type genes in $\mathrm{H}$. alvei were hall and halR, respectively.
The water molecules associated with the protein model were removed and the missing hydrogen atoms were supplemented using Clean Protein module of Discovery Studio (DS). The $3 \mathrm{D}$ structures of the ligands including L-carvone, halogenated furanone C30 (a known QSI), and $\mathrm{C}_{6}$-HSL were downloaded from the ZINC 12 database $^{3}$ and optimized in DS to obtain their possible lowest-energy conformations. The binding spheres that covered the active site residues were also obtained with DS, using the Define and Edit Binding Site module. Finally, docking of the ligands was subsequently performed using the Libdock algorithm.

\section{Statistical Analysis}

Each experiment was performed in triplicate, and the data were presented as the mean values $\pm \mathrm{SD}$. The data were analyzed by one-way analysis of variance (ANOVA) along with Tukey test correction using the software SPSS Statistics 20.0. Graphs were constructed using Origin Pro 9.0. Differences with a $p$-value $<0.05$ were considered significant.

\section{RESULTS}

\section{Minimum Inhibitory Concentration (MIC) of L-Carvone}

The MIC of L-carvone, with concentrations ranging from 0.0625 to $2 \mu \mathrm{L} / \mathrm{mL}$, was estimated by the Oxford cup method. It was observed that the MIC of L-carvone for C. violaceum CV026 was $1.0 \mu \mathrm{L} / \mathrm{mL}$; L-carvone did not influence the growth of $H$. alvei at the same concentration. Therefore, the sub-MICs $(0.5,0.25$, 0.125 , and $0.0625 \mu \mathrm{L} / \mathrm{mL}$ ) were selected for further experiments in this study.

\section{Effect of L-Carvone on Violacein Production in C. violaceum CV026}

To determine whether L-carvone at the sub-MICs inhibited violacein production in CV026, two assays were performed. Figure 1A shows that a clear inhibitory zone was observed around the well on the purple pigment plate due to L-carvone; however, the control, sterile water, did not inhibit pigment production. Furthermore, the quantitative results of violacein production were obtained. L-Carvone showed a dose-dependent QSI activity and did not significantly inhibit bacterial growth at the sub-MICs (Figure 1B). The minimum violacein production rate (OD treatment group/OD control group) was only $48.25 \%$ at a $0.5 \mu \mathrm{L} / \mathrm{mL}$ concentration of L-carvone.

\section{Effect of L-Carvone on Biofilm Formation in $\mathrm{H}$. alvei}

The results of biofilm formation after treatment with different concentrations of L-carvone are presented in Table 2 . A minimum biofilm inhibition of $13.43 \%$ was observed when $H$. alvei was cultured with $\mathrm{L}$-carvone at $0.0625 \mu \mathrm{L} / \mathrm{mL}$;

\footnotetext{
${ }^{3}$ http://zinc.docking.org/
} 

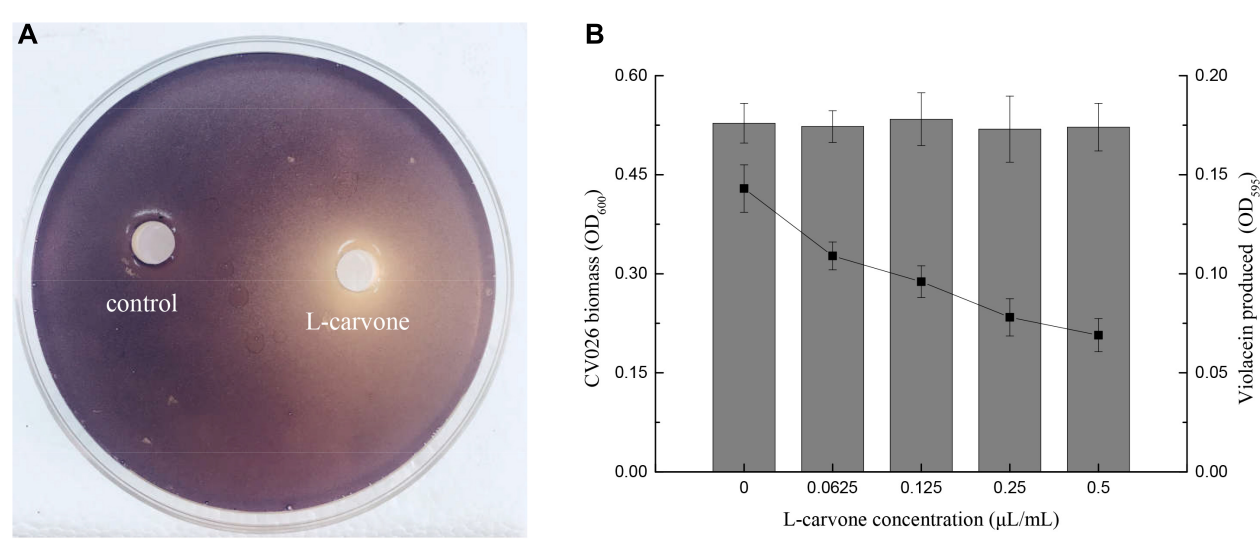

FIGURE 1 | Violacein inhibitory activity of L-carvone. (A) Inhibitory activity of L-carvone on the violacein production of CV026. (B) Quantitative analysis of CV026 biomass (columns) and violacein production (lines) at sub-inhibitory concentrations of L-carvone.

TABLE 2 | Inhibitory activity of L-carvone on biofilm formation by $\mathrm{H}$. alvei (mean \pm standard deviation).

\begin{tabular}{llcc}
\hline Additive & Concentration & Biofilm formation $^{\mathbf{a}}$ & Inhibitory rate (\%) $^{\mathbf{b}}$ \\
\hline $\mathrm{C}_{6}$-HSL & $20 \mu \mathrm{g} / \mathrm{mL}$ & $0.951 \pm 0.004^{\mathrm{c}}$ & - \\
Control & $0 \mu \mathrm{L} / \mathrm{mL}$ & $0.685 \pm 0.004^{\mathrm{d}}$ & - \\
L-carvone & $0.0625 \mu \mathrm{L} / \mathrm{mL}$ & $0.593 \pm 0.007^{\mathrm{e}}$ & 13.43 \\
L-carvone & $0.125 \mu \mathrm{L} / \mathrm{mL}$ & $0.532 \pm 0.010^{\mathrm{e}}$ & 15.30 \\
L-carvone & $0.25 \mu \mathrm{L} / \mathrm{mL}$ & $0.478 \pm 0.003^{\mathrm{f}}$ & 30.32 \\
L-carvone & $0.5 \mu \mathrm{L} / \mathrm{mL}$ & $0.326 \pm 0.005^{\mathrm{g}}$ & 52.41
\end{tabular}

${ }^{a}$ Expressed as $O D_{595}$ after incubation with crystal violet. ${ }^{b}$ The inhibitory rate $=(O D$ control group - $O D$ treated group)/OD control group. ${ }^{c-g}$ Significantly different means $(P<0.05)$.

a maximum biofilm inhibition of $52.41 \%$ was observed at am $\mathrm{L}$-carvone concentration of $0.5 \mu \mathrm{L} / \mathrm{mL}$. In contrast, biofilm formation in the $\mathrm{C}_{6}$-HSL-treated group was visibly higher than that in the control group, which proves that the biofilm formation of $H$. alvei is positively regulated by the AHL-based QS system.

In this study, the biofilm states of the $H$. alvei strain in the presence of various concentrations of L-carvone were also observed by CLSM and SEM. The CLSM images showed thick and dense biofilms after $\mathrm{C}_{6}$-HSL treatment, compared with the control group (Figure $\mathbf{2 A}$ ), whereas L-carvone treatment significantly removed the microbes attached to the zinc surface (Figure 2A). The SEM images displayed similar results and showed a major disruption to the biofilm architecture as well as the reduction of the biofilm matrix (Figure 2B).

\section{Effect of L-Carvone on Swimming and Swarming Motility of $\boldsymbol{H}$. alvei}

The migration distance of $H$. alvei grown on swimming and swarming agar plates at $28^{\circ} \mathrm{C}$ for $48 \mathrm{~h}$ is shown in Figure 3 . The treatment of $H$. alvei with sub-MICs of L-carvone reduced the swimming motility significantly; the level of swimming motility inhibition due to L-carvone $(0.0625-0.5 \mu \mathrm{L} / \mathrm{mL})$ was 12.43-61.49\%, as depicted in Supplementary Table S1. Similarly, swarming migration of $H$. alvei was also impaired considerably (23.29-74.94\%) after treatment with L-carvone (Supplementary Table S1). However, the treatment of $H$. alvei with $\mathrm{C}_{6}-\mathrm{HSL}$ promoted its motility.

\section{Effect of L-Carvone on AHL Production in $H$. alvei}

To investigate the effect of L-carvone on AHL production of test strain, the AHLs in the ethyl acetate crude extract of $H$. alvei were analyzed using GC-MS. After the AHL standards were separated individually, and their retention times were identified (Supplementary Figure S1A), we calculated the relative quantity of AHLs in the crude extracts based on the ratio of the peak area of the samples to that of the internal standard $\left(\mathrm{C}_{14}-\mathrm{HSL}\right)$. The AHL types observed in the $H$. alvei crude extracts were $\mathrm{C}_{6}$-HSL and $\mathrm{C}_{8}$-HSL, at concentrations of $2.16 \pm 0.06$ and $2.27 \pm 0.12 \mu \mathrm{g} / \mathrm{mL}$, respectively. Treatment with L-carvone significantly reduced the AHL production (Supplementary Figure S1C); when treated with $0.5 \mu \mathrm{L} / \mathrm{mL}$ L-carvone, the minimal concentrations of $\mathrm{C}_{6}$-HSL and $\mathrm{C}_{8}$-HSL decreased to $0.16 \pm 0.09$ and $0.97 \pm 0.04 \mu \mathrm{g} / \mathrm{mL}$, respectively (Supplementary Figure S1B).

\section{RT-qPCR}

The RT-qPCR experiments were performed to understand the effect of L-carvone on the expression level of QS-regulated genes in $H$. alvei. The selected genes were lux-type genes, named hall and halR, respectively. Because in this QS system, the halI gene regulated AHL biosynthesis by encoding Hall (the AHL synthase), the halR gene responded to the corresponding AHL by encoding HalR (the transcriptional regulator), and further regulated the transcription of the downstream genes. The results obtained in this study show that L-carvone could selectively affect the QS system by significantly downregulating the relative expression levels of halI and halR (Figure 4). $\mathrm{C}_{6}$-HSL, which was used as the positive control, could significantly upregulate the expression of the selected genes. Melt and amplification curves of the genes were established in Supplementary Figure S3. 
A
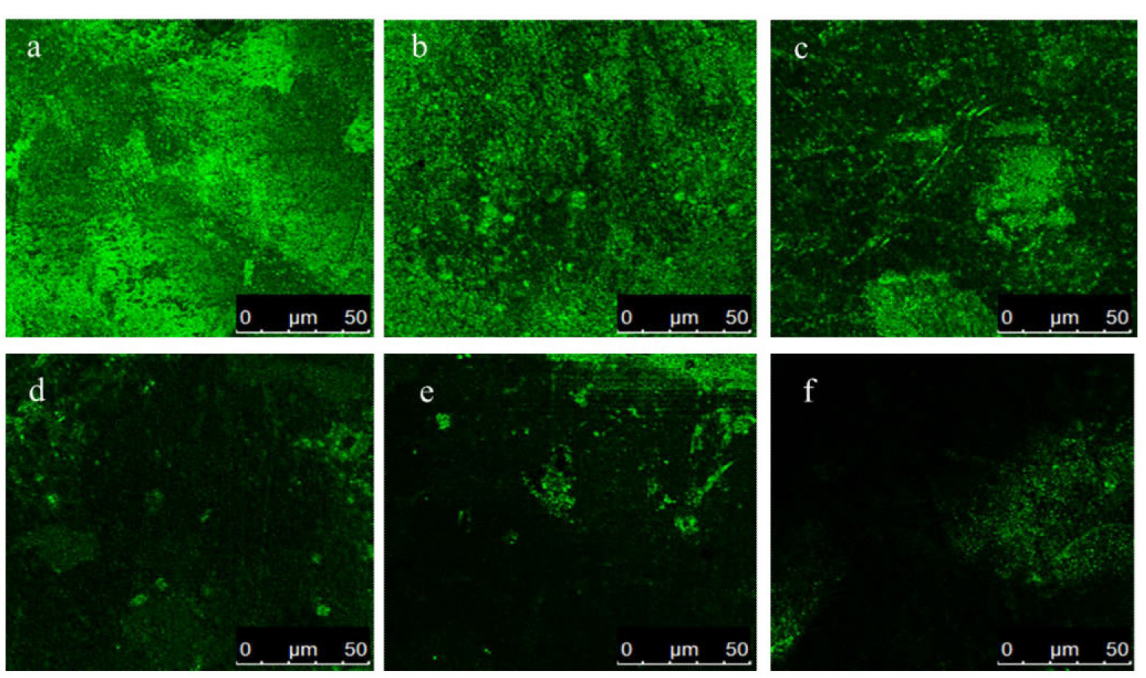

B
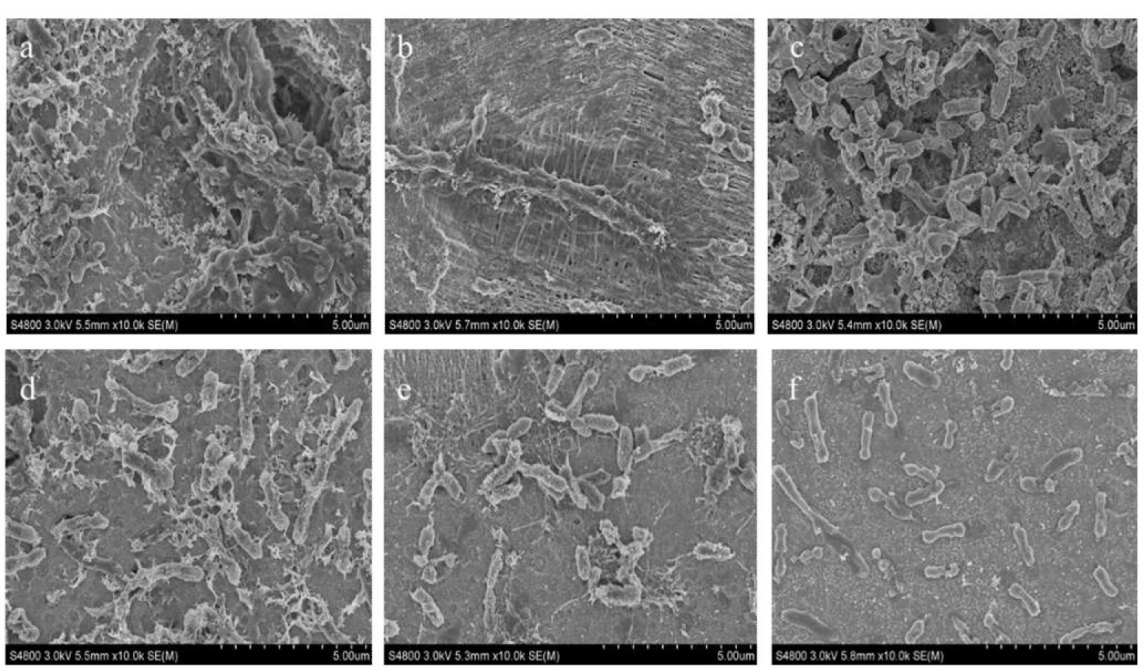

FIGURE 2 | Confocal laser scanning microscopy (CLSM) images (A) and SEM images (B) of the biofilm states of the $H$. alvei strain on zinc surfaces after different treatments. (a) $20 \mu \mathrm{g} / \mathrm{mL} \mathrm{C}_{6}-\mathrm{HSL}$, (b) control, (c-f) L-carvone treatments at concentrations of 0.0625, 0.125, 0.25, and $0.5 \mu \mathrm{L} / \mathrm{mL}$.

\section{Homology Modeling and Model Assessment}

At present, the three-dimensional (3D) structures of the HalI and HalR proteins have not yet been analyzed; therefore, homology modeling, based on the online tool SWISS-MODEL, was utilized to solve this problem. Modeling templates were matched using the amino acid sequences of Hall (acyl-homoserine-lactone synthase, AAP30849.1) and HalR (transcriptional regulators, AAP30848.1); the top 50 templates of each protein were obtained. The three best models of HalI and HalI proteins are listed in Supplementary Table S2, based on sequence similarities and the GMQE scores.

Model qualities were assessed by using QMEAN, which is a composite estimator and provides both global and local absolute quality estimates for models (Benkert et al., 2011). QMEAN
$Z$-Scores of around zero are an indication of a high quality for a model; however, scores of -4.0 or lower indicated a low quality. Therefore, the results in Supplementary Figures S2A-D show that the best models for HalI and HalR proteins were the 1k4j.1.A (score of -1.85) and 5107.1.B (score of -1.37) models, respectively; they were able to efficiently predict the $3 \mathrm{D}$ structures of Lux-type proteins in $H$. alvei.

\section{In silico Analysis}

In silico analysis studies of L-carvone provide an insight into the binding affinity of this potential QSI, with the model of HalI and HalR protein. For the QS transcriptional receptor HalR protein, the halogenated furanone $\mathrm{C} 30$ and $\mathrm{C}_{6}$-HSL were docked as the control ligands. As shown in Supplementary Table S3, L-carvone docked with the active site of the HalI 
A
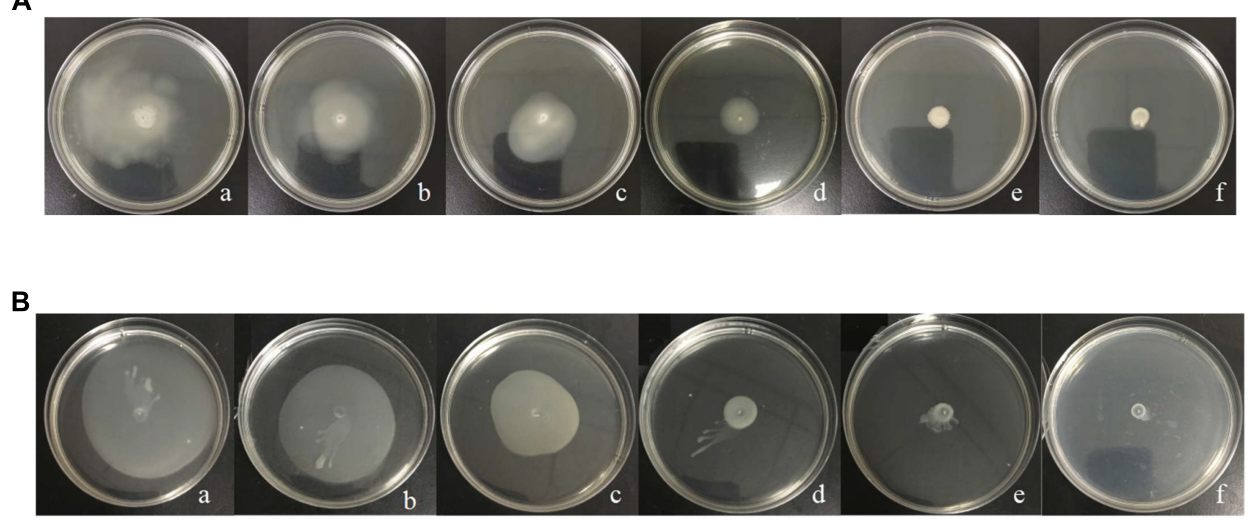

FIGURE 3 | Analysis of the inhibition of the motility of $H$. alvei by L-carvone. Swimming (A) and swarming (B) agar plates were incubated at $28^{\circ} \mathrm{C}$ and monitored after 48 h. (a) $20 \mu \mathrm{g} / \mathrm{mL}$ C6-HSL, (b) control, (c-f) $0.0625,0.125,0.25$, and $0.50 \mu \mathrm{L} / \mathrm{mL}$ L-carvone.

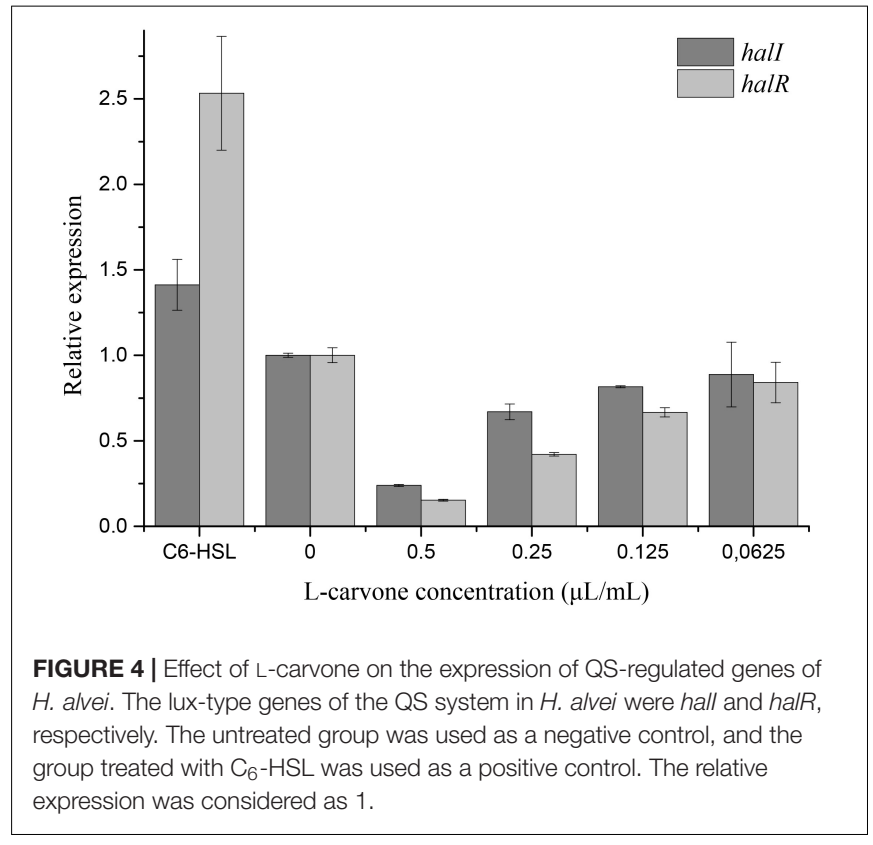

protein of $H$. alvei, with a LibDock score of 71.0676. Moreover, L-carvone (LibDock score of 66.7963) showed a better affinity toward HalR than the standard QSI, halogenated furanone C30 (LibDock score of 52.7221). However, both the ligands were observed to have a lower affinity toward HalR than the natural ligand $\mathrm{C}_{6}$-HSL (LibDock score of 84.7765). Figure 4 depicts the possible mechanism of the action of L-carvone in attenuating QS-regulated virulence factor and biofilm production in H. alvei.

\section{DISCUSSION}

There is increasing evidence that plant essential oils can act as potential QSIs, to reduce QS-mediated production of virulence factors and biofilms in microorganisms, and provide a new insight into controlling microbial communities (Zhang et al., 2018). Our data support this notion, revealing a potential QSI, L-carvone (the main component of spearmint essential oil), which interferes with violacein expression in C. violaceum CV026 and enters $H$. alvei, reducing its motility, biofilm formation, and expression of QS-related genes.

In this study, originally, sub-MICs of L-carvone were tested for their QSI activity using the CV026 strain (Figure 1). The biosensor strain CV026 can only respond to exogenous short-chain AHLs through the cytoplasmic transcription factor CviR (a LuxR homolog), which activates the expression of violacein in combination with the AHLs (McClean et al., 1997). Many studies have revealed that the reduction of violacein production without the growth of CV026 being affected is considered a direct evidence for the interference of the QS system (Venkadesaperumal et al., 2016; Liu et al., 2017). Based on the above evidences, this work further explored the QS interference activity of L-carvone on $H$. alvei, since the QS-mediated production of virulence factors and biofilms plays a key role in the growth of this spoilage organism (Hou et al., 2017b).

The bacterial cells in biofilms are more resistant to antiseptics and food processing conditions; this is likely to cause serious food safety issues (Bai and Rai, 2011). Consequently, studies on preventing biofilm formation are garnering special interest. Previous studies have indicated that the effects of L-carvone on biofilms of Gram-positive and Gram-negative bacteria are possibly different. Soumya et al. (2011) reported that the sub-MICs of L-carvone could reduce biofilm formation in Pseudomonas aeruginosa as a natural QS-inhibitory compound. However, in case of Gram-positive bacteria, the study by Leonard et al. (2010) indicated that carvone could increase biofilm production in Listeria monocytogenes, rather than inhibiting its production. Interestingly, Oliveroverbel et al. (2014) also showed that carvone could inhibit violacein and pyocyanin production in 


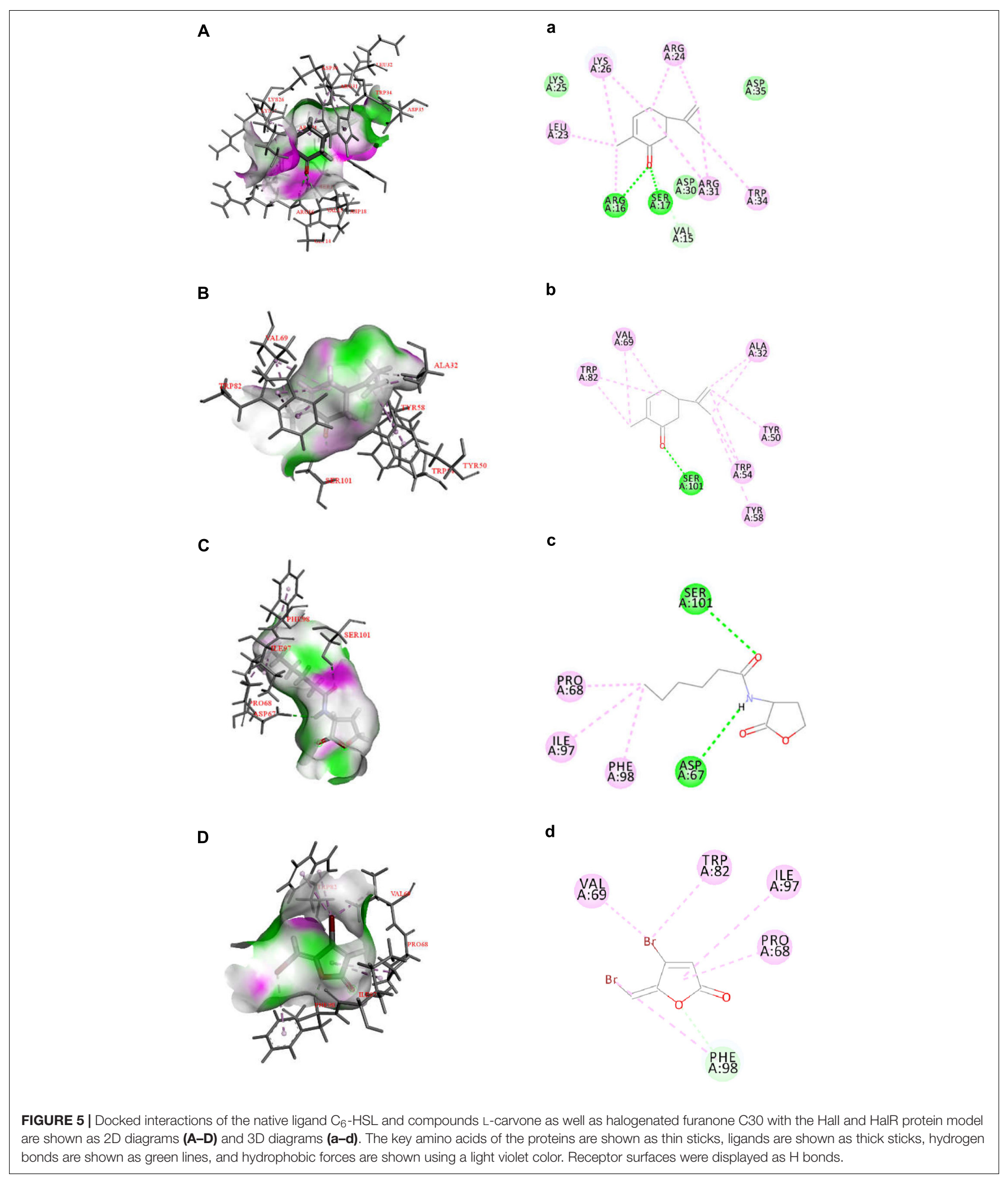

C. violaceum and $P$. aeruginosa, respectively, by interfering with their QS systems, and found that this inhibition was produced by its levorotary analog. Herein, for the first time, we have reported that at sub-MICs, L-carvone, a potential natural QSI, could significantly reduce biofilm formation by $H$. alvei at $28^{\circ} \mathrm{C}$ on polypropylene and zinc surfaces (Table 2 
and Figure 2). This result was similar to those of the reports of Soumya and Oliveroverbel. A maximum inhibition of $52.41 \%$ was observed using a microplate photometer. Furthermore, in situ analysis of the biofilm matrix performed using SEM and LCSM was able to provide further information on the structure of the formed biofilms following different treatments (Azeredo et al., 2017). As reported by Gross (2017), biofilms were seen as 'Microbial cities' that included both infrastructure (generally embedded in polysaccharide matrixes) and social communication. CLSM and SEM images in our study clearly displayed a major disruption to this infrastructure and the reduction to the biofilm matrix (Figure 2). These results were similar to those of the study by Zhou et al. (2018), who found the Hordenine (a sprouting barley extract) could act as a novel QSI and inhibit biofilm formation in P. aeruginosa.

Quorum sensing-regulated flagellar-dependent motility (like swimming and swarming) is closely associated with biofilm formation. In addition, this motility (QS-regulated flagellar-dependent motility) is considered as a virulence factor because of its fundamental role in adhesion, colonization, and virulence expression of pathogens (Atkinson et al., 2006; Bluskadosh et al., 2013). Therefore, a decrease in motility would likely control the biofilm formation of $H$. alvei and weaken its infection ability. In the present study, treatments with L-carvone dose dependently inhibited the migration capacity of $H$. alvei. An L-carvone concentration of $0.5 \mu \mathrm{L} / \mathrm{mL}$ showed that the maximum inhibition levels of swimming and swarming motility were 61.49 and $74.94 \%$, respectively. These results are consistent with those from an earlier study by Hou et al. (2017a), who demonstrated a significant inhibition of motility in $H$. alvei by the food additive dihydrocoumarin.

Due to the essential role of AHLs on the QS system, the effects of L-carvone treatment were characterized using GC-MS, and major changes in the AHL production by the $H$. alvei strain were observed. GC-MS, with the electron ionization mode, is a powerful tool for the rapid, easy, and selective determination of the AHL levels (Cataldi et al., 2004). The results indicated that $\mathrm{L}$-carvone was able to significantly inhibit the production of both the primary AHLs $\left(\mathrm{C}_{6}-\mathrm{HSL}\right.$ and $\left.\mathrm{C}_{8}-\mathrm{HSL}\right)$ in $H$. alvei, especially reducing the $\mathrm{C}_{6}$-HSL production from 2.16 to $0.16 \mu \mathrm{g} / \mathrm{mL}$. Similarly, Luciardi et al. (2016) found that volatiles from food and medicinal plants could interfere with QS-mediated virulence expression in $P$. aeruginosa by reducing the biosynthesis of AHLs.

Quorum sensing in Gram-negative bacteria is predominantly controlled by LuxI/R-type proteins, which regulate the production of AHLs, expression of virulence factors, and formation of biofilms (Fuqua et al., 1994). To investigate the inhibitory mechanism of L-carvone on the QS system of $H$. alvei, relevant protein-molecular interactions were firstly evaluated by in silico analysis. According to the in silico results, we noticed high LibDock scores of the docking of L-carvone with the HalI (LuxI-type protein) and HalR (the LuxR-type protein) of $H$. alvei (Supplementary Table S3). In HalI, Lcarvone was well embedded into a cavity in the vicinity of the active site, the key residues of which included ARG16, SER17, VAL15, ARG31, TRP34, ARG24, LYS26, and LEU23. Simultaneously, L-carvone formed three hydrogen bonds with ARG16, SER17, and VAL15 and showed a hydrophobic behavior with the other residues, as shown in Figures 5A,a. In HalR, L-carvone formed one hydrogen bond with SER101 and interacted with other residues (TRP82, VAL69, ALA32, TYR50, TRP54, TYR58, and SER101) via the hydrophobic effect (Figures 5B,b). $\mathrm{C}_{6}$-HSL, as a positive control, formed two hydrogen bonds with SER101 and ASP67 (Figures 5C,c). However, the standard QSI, halogenated furanone C30, as a negative control, did not form any hydrogen bonds with HalR (Figures 5D,d).

The hydrogen-bonding interactions are considered to play a major role in the process where ligands dock with the LuxR-type receptor (Gerdt et al., 2015). In our study, L-carvone showed a better in silico affinity toward HalR than the halogenated furanone C30, because of a higher LibDock score and additional hydrogen bonds. L-carvone and $\mathrm{C}_{6}$-HSL can form hydrogen bonds with the HalR protein at a common site, SER101, indicating a possible competitive action between them. Combined with the GC-MS results, these data confirm that the inhibitory mechanism of L-carvone on the QS system of $H$. alvei might involve the interaction of L-carvone with the HalI protein and subsequent interference of AHL biosynthesis in $H$. alvei. In addition, we also characterized the effects of L-carvone treatment using transcriptomics, and observed that the halI and halR genes were significantly downregulated in $H$. alvei, similar to the results reported in a previous research study (Zhou et al., 2018). The RT-qPCR results were consistent with those of the in silico analysis, which enhanced the credibility of the QS inhibitory mechanism of L-carvone.

\section{CONCLUSION}

In summary, the present study demonstrates that L-carvone had a significant inhibitory activity on the QS system by reducing the AHL-mediated production of virulence factors and biofilm formation in $H$. alvei. More specifically, Lcarvone combined with the AHL synthase HalI via hydrogen bonds, which led to the disruption of AHL biosynthesis. Understanding the roles and functions of QS in food ecosystems can help in preventing the colonization of food surfaces, toxin formation, and proliferation of food-related bacteria. Therefore, L-carvone, with a QS inhibitory activity, is a promising agent for controlling foodborne pathogens and improving food safety.

\section{AUTHOR CONTRIBUTIONS}

TL and YM contributed to the conception of the study. YM performed the data analyses and wrote the manuscript. $\mathrm{BH}$ and XS contributed significantly to analysis and manuscript 
preparation. JL helped to perform the analysis with constructive discussions. All authors contributed to manuscript revision, read and approved the submitted version.

\section{FUNDING}

This study was supported by a grant from the National Natural Science Foundation of China (No. 31471639) and the National

\section{REFERENCES}

Almeida, F. A., Pinto, U. M., and Vanetti, M. C. (2016). Novel insights from molecular docking of SdiA from Salmonella enteritidis and Escherichia coli with quorum sensing and quorum quenching molecules. Microb Pathog. 99, 178-190. doi: 10.1016/j.micpath.2016.08.024

Atkinson, S., Chang, C. Y., Sockett, R. E., Cámara, M., and Williams, P. (2006). Quorum sensing in Yersinia enterocolitica controls swimming and swarming motility. J. Bacteriol. 188, 1451-1461. doi: 10.1128/JB.188.4.1451-1461.2006

Azeredo, J., Azevedo, N. F., Briandet, R., Cerca, N., Coenye, T., Costa, A. R., et al. (2017). Critical review on biofilm methods. Crit. Rev. Microbiol. 43, 313-351. doi: 10.1080/1040841X.2016.1208146

Bai, A. J., and Rai, V. R. (2011). Bacterial quorum sensing and food industry. Compr. Rev. Food Sci. F 10, 183-193. doi: 10.1111/j.1541-4337.2011.00150.x

Benkert, P., Biasini, M., and Schwede, T. (2011). Toward the estimation of the absolute quality of individual protein structure models. Bioinformatics 27, 343-350. doi: 10.1093/bioinformatics/btq662

Bertoni, M., Kiefer, F., Biasini, M., Bordoli, L., and Schwede, T. (2017). Modeling protein quaternary structure of homo- and hetero-oligomers beyond binary interactions by homology. Sci. Rep. 7:10480. doi: 10.1038/s41598-017-09654-8

Bienert, S., Waterhouse, A., de Beer, T. A. P., Tauriello, G., Studer, G., Bordoli, L., et al. (2017). The SWISS-MODEL Repository-new features and functionality. Nucleic Acids Res. 45, D313-D319. doi: 10.1093/nar/gkw1132

Bluskadosh, I., Zilka, A., Yerushalmi, G., and Banin, E. (2013). The effect of pstS and phoB on quorum sensing and swarming motility in Pseudomonas aeruginosa. PLoS One 8:e74444. doi: 10.1371/journal.pone.0074444

Cataldi, T. R. I., Bianco, G., Frommberger, M., and Schmitt-Kopplin, P. (2004). Direct analysis of selected N-acyl-l-homoserine lactones by gas chromatography/mass spectrometry. Rapid Commun. Mass. Sp. 18, 1341-1344. doi: $10.1002 / \mathrm{rcm} .1480$

Chen, T. R., Wei, Q. K., and Chen, Y. J. (2011). Pseudomonas spp. and hafnia alvei growth in UHT milk at cold storage. Food Control. 22, 697-701. doi: 10.1016/j.foodcont.2010.10.004

Choo, J. H., Rukayadi, Y., and Hwang, J. K. (2006). Inhibition of bacterial quorum sensing by Vanilla extract. Lett. Appl. Microbiol. 42, 637-641. doi: 10.1111/j. 1472-765X.2006.01928.x

de Carvalho, C. C. C. R., and da Fonseca, M. M. R. (2006). Carvone: why and how should one bother to produce this terpene. Food Chem. 95, 413-422. doi: 10.1016/j.foodchem.2005.01.003

de la Fuente-Núñez, C., Korolik, V., Bains, M., Nguyen, U., Breidenstein, E. B., Horsman, S., et al. (2012). Inhibition of bacterial biofilm formation and swarming motility by a small synthetic cationic peptide. Antimicrob Agents Ch. 56:2696. doi: 10.1128/AAC.00064-12

Defoirdt, T. (2017). Quorum-sensing systems as targets for antivirulence therapy. Trends Microbiol. 26, 313-328. doi: 10.1016/j.tim.2017.10.005

Defoirdt, T., Brackman, G., and Coenye, T. (2013). Quorum sensing inhibitors: how strong is the evidence? Trends Microbiol. 21, 619-624. doi: 10.1016/j.tim. 2013.09.006

Diao, W. R., Zhang, L. L., Feng, S. S., and Xu, J. G. (2014). Chemical composition, antibacterial activity, and mechanism of action of the essential oil from Amomum kravanh. J. Food Protect. 77:1740. doi: 10.4315/0362-028X.JFP14-014

Ding, T., Li, T. T., Wang, Z., and Li, J. (2017). Curcumin liposomes interfere with quorum sensing system of Aeromonas sobria and in silico analysis. Sci. Rep. 7:8612. doi: 10.1038/s41598-017-08986-9
Key R\&D Program of China (Nos. 2018YFD0400601 and 2017YFD0400106).

\section{SUPPLEMENTARY MATERIAL}

The Supplementary Material for this article can be found online at: https://www.frontiersin.org/articles/10.3389/fmicb. 2018.03324/full\#supplementary-material

Fitzgerald, D. J., Stratford, M., and Narbad, A. (2003). Analysis of the inhibition of food spoilage yeasts by vanillin. Int. J. Food Microbiol. 86, 113-122. doi: 10.1016/S0168-1605(03)00059-X

Friedman, M., Henika, P. R., and Mandrell, R. E. (2002). Bactericidal activities of plant essential oils and some of their isolated constituents against Campylobacter jejuni, Escherichia coli, Listeria monocytogenes, and Salmonella enterica. J. Food Protect. 65, 1545-1560. doi: 10.4315/0362-028X-65.10. 1545

Fuqua, W. C., Winans, S. C., and Greenberg, E. P. (1994). Quorum sensing in bacteria: the luxR-luxI family of cell density-responsive transcriptional regulators. J. Bacteriol. 176, 269-275. doi: 10.1128/jb.176.2.269-275. 1994

Gerdt, J. P., Mcinnis, C. E., Schell, T. L., and Blackwell, H. E. (2015). Unraveling the contributions of hydrogen-bonding interactions to the activity of native and non-native ligands in the quorum-sensing receptor LasR. Org. Biomol. Chem. 13, 1453-1462. doi: 10.1039/C4OB02252A

Gross, M. (2017). Shining new light on quorum sensing. Curr. Biol. 27, R1293-R1296. doi: 10.1016/j.cub.2017.11.068

Hou, H. M., Jiang, F., Zhang, G. L., Wang, J. Y., Zhu, Y. H., and Liu, X. Y. (2017a). Inhibition of Hafnia alvei H4 biofilm formation by the food additive dihydrocoumarin. J. Food Protection. 80:842. doi: 10.4315/0362-028X.JFP16-460

Hou, H. M., Zhu, Y. L., Wang, J. Y., Jiang, F., Qu, W. Y., Zhang, G. L., et al. (2017b). Characteristics of $N$-acylhomoserine lactones produced by Hafnia alvei H4 isolated from spoiled instant sea cucumber. Sensors 17:772. doi: 10. 3390/s17040772

Husain, F. M., Ahmad, I., Khan, M. S., Ahmad, E., Tahseen, Q., Khan, M. S., et al. (2015). Sub-MICs of Mentha piperita essential oil and menthol inhibits AHL mediated quorum sensing and biofilm of Gram-negative bacteria. Front. Microbiol. 6:420. doi: 10.3389/fmicb.2015.00420

Ia, S. V. P., Agilandeswari, P., Musthafa, K. S., Karutha, P. S., and Veera, R. A. (2012). Antibiofilm and quorum sensing inhibitory potential of Cuminum cyminum and its secondary metabolite methyl eugenol against gram negative bacterial pathogens. Food Res. Int. 45, 85-92. doi: 10.1016/j.foodres.2011. 10.022

Kennedy, J. E., Oblinger, J. L., and West, R. L. (2010). Fate of Salmonella infantis, Staphylococcus aureus, and Hafnia alvei in vacuum packaged beef plate pieces during refrigerated storage. J. Food Sci. 45, 1273-1277. doi: 10.1111/j.13652621.1980.tb06536.x

Kumar, N. V., Murthy, P. S., Manjunatha, J. R., and Bettadaiah, B. K. (2015). Synthesis and quorum sensing inhibitory activity of key phenolic compounds of ginger and their derivatives. Food Chem. 159, 451-457. doi: 10.1016/j. foodchem.2014.03.039

Leonard, C. M., Virijevic, S., Regnier, T., Combrinck, S., Jürgens, A., and Viljoen, A. M. (2010). Bioactivity of selected essential oils and some components on Listeria monocytogenes biofilms. S. Afr. J. Bot. 76, 676-680. doi: 10.1016/j.sajb. 2010.07.002

Liu, Z., Pan, Y., Li, X., Jie, J., and Zeng, M. (2017). Chemical composition, antimicrobial and anti-quorum sensing activities of pummelo peel flavonoid extract. Ind. Crop Prod. 109, 862-868. doi: 10.1016/j.indcrop.2017.09.054

Livak, K. J., and Schmittgen, T. D. (2001). Analysis of relative gene expression data using real-time quantitative PCR and the 2- $\Delta \Delta$ CTmethod. Methods 25, 402-408. doi: 10.1006/meth.2001.1262

Luciardi, M. C., Pérez, H. M. V., Nora, M., Alicia, B., Arena, M. E., and Elena, C. (2016). Volatiles from subtropical convolvulaceae that interfere with bacterial 
cell-to-cell communication as potential antipathogenic drugs. Evid. Based. Compl. Alt. 121, 1-8. doi: 10.1155/2016/7890260

McClean, K. H., Winson, M. K., Fish, L., Taylor, A., Chhabra, S. R., Camara, M., et al. (1997). Quorum sensing and Chromobacterium violaceum: exploitation of violacein production and inhibition for the detection of $\mathrm{N}$-acylhomoserine lactones. Microbioloy 143, 3703-3711. doi: 10.1099/00221287-143-12-3703

Ng, W. L., and Bassler, B. L. (2009). Bacterial quorum-sensing network architectures. Annu. Rev. Genet. 43:197. doi: 10.1146/annurev-genet-102108134304

Oliveroverbel, J., Barretomaya, A., Bertelsevilla, A., and Stashenko, E. E. (2014). Composition, anti-quorum sensing and antimicrobial activity of essential oils from Lippia alba. Braz. J. Microbiol. 45, 759-767. doi: 10.1590/S151783822014000300001

Porfírio, E. M., Melo, H. M., Pereira, A. M. G., Cavalcante, T. T. A., Gomes, G. A., de Carvalho, M. G., et al. (2017). In vitro antibacterial and antibiofilm activity of Lippia alba essential oil, citral, and carvone against Staphylococcus aureus. Sci. World J. 2017, 1-7. doi: 10.1155/2017/4962707

Rode, T. M., Langsrud, S., Holck, A., and Møretrø, T. (2007). Different patterns of biofilm formation in Staphylococcus aureus under food-related stress conditions. Int. J. Food Microbiol. 116, 372-383. doi: 10.1016/j.ijfoodmicro. 2007.02.017

Soumya, E. A., Abdellah, H., Remmal, A., Saad, I. K., Hassan, L., and Remmal, A. (2011). In vitro activity of four common essential oil components against biofilm-producing Pseudomonas aeruginosa. Res. J. Microbiol. 6, 394-401. doi: 10.3923/jm.2011.394.401

Tan, J.-Y., Yin, W.-F., and Chan, K.-G. (2014). Quorum sensing activity of Hafnia alvei isolated from packed food. Sensors 14, 6788-6796. doi: 10.3390/ s140406788

Venkadesaperumal, G., Rucha, S., Sundar, K., and Shetty, P. H. (2016). Antiquorum sensing activity of spice oil nanoemulsions against food borne pathogens. LWT-Food Sci. Technol. 66, 225-231. doi: 10.1016/j.lwt.2015. 10.044
Viana, E. S., Campos, M. E., Ponce, A. R., Mantovani, H. C., and Vanetti, M. C. (2009). Biofilm formation and acyl homoserine lactone production in Hafnia alvei isolated from raw milk. Biol. Res. 42, 427-436.

Vivas, J., Padilla, D., Real, F., Bravo, J., Grasso, V., and Acosta, F. (2008). Influence of environmental conditions on biofilm formation by Hafnia alvei strains. Vet. Microbiol. 129, 150-155. doi: 10.1016/j.vetmic.2007.11.007

Waterhouse, A., Bertoni, M., Bienert, S., Studer, G., Tauriello, G., Gumienny, R., et al. (2018). Swiss-model: homology modelling of protein structures and complexes. Nucleic Acids Res. 46, W296-W303. doi: 10.1093/nar/gky427

Zhang, Y., Kong, J., Xie, Y., Guo, Y., Cheng, Y., Qian, H., et al. (2018). Essential oil components inhibit biofilm formation in Erwinia carotovora and Pseudomonas fluorescens via anti-quorum sensing activity. LWT-Food Sci. Technol. 92, 133-139. doi: 10.1016/j.lwt.2018.02.027

Zhou, J. W., Luo, H. Z., Jiang, H., Jian, T. K., Chen, Z. Q., and Jia, A. Q. (2018). Hordenine, a novel quorum sensing inhibitor and anti-biofilm agent against Pseudomonas aeruginosa. J. Agric. Food Chem. 66, 1620-1628. doi: 10.1021/acs. jafc. $7 \mathrm{~b} 05035$

Zhu, J., Zhao, A., Feng, L., and Gao, H. (2016). Quorum sensing signals affect spoilage of refrigerated large yellow croaker (Pseudosciaena crocea) by Shewanella baltica. Int. J. Food Microbiol. 217, 146-155. doi: 10.1016/j. ijfoodmicro.2015.10.020

Conflict of Interest Statement: The authors declare that the research was conducted in the absence of any commercial or financial relationships that could be construed as a potential conflict of interest.

Copyright $\odot 2019 \mathrm{Li}, \mathrm{Mei}, \mathrm{He}$, Sun and Li. This is an open-access article distributed under the terms of the Creative Commons Attribution License (CC BY). The use, distribution or reproduction in other forums is permitted, provided the original author(s) and the copyright owner(s) are credited and that the original publication in this journal is cited, in accordance with accepted academic practice. No use, distribution or reproduction is permitted which does not comply with these terms. 